\title{
The effect of the research setting on the emotional and sensory profiling under blind, expected, and informed conditions: A study on premium and private label yogurt products
}

\author{
Joachim J. Schouteten, ${ }^{* 1}$ Hans De Steur, ${ }^{*}$ Benedikt Sas, $†$ Ilse De Bourdeaudhuij, $\ddagger$ and Xavier Gellynck* \\ *SensoLab, Department of Agricultural Economics, \\ †Department of Food Safety and Food Quality, Ghent University, Coupure links 653, Gent 9000, Belgium \\ ‡Department of Movement and Sport Sciences, Ghent University, Watersportlaan 2, Gent 9000, Belgium
}

\begin{abstract}
Although sensory and emotional evaluation of food products mostly occurs in a controlled laboratory environment, it is often criticized as it may not reflect a realistic situation for consumers. Moreover, products are mainly blind evaluated by participants, whereas external factors such as brand are often considered as key drivers of food choice. This study aims to examine the role of research setting (central location test versus home-use test) and brand information on the overall acceptance, and sensory and emotional profiling of 5 strawberry-flavored yogurts. Thereby, private label and premium brands are compared under 3 conditions: blind, expected, and informed (brand information). A total of 99 adult subjects participated in 3 sessions over 3 consecutive weeks. Results showed that overall liking for 2 yogurt samples was higher in the laboratory environment under the informed evaluation condition, whereas no effect of research setting was found under the blind and expected conditions. Although emotional profiles of the products differed depending on the research setting, this was less the case for the sensory profiles. Furthermore, brand information clearly affected the sensory perception of certain attributes but had less influence on overall liking and emotional profiling. These results indicate that both scientists and food companies should consider the effect of the chosen methodology on ecological validity when conducting sensory research with consumers because the laboratory context could lead to a more positive evaluation compared with a home-use test.
\end{abstract}

Key words: context, brand, consumer, EmoSensory Wheel

Received May 20, 2016.

Accepted September 20, 2016.

${ }^{1}$ Corresponding author: Joachim.Schouteten@UGent.be

\section{INTRODUCTION}

Overall acceptance is widely used as a sensory measurement to gain insight in food choice and preference (Lawless and Heymann, 2010). But although this measurement has been widely applied by both scientists and industry, the food industry is still confronted with high market failure rates despite sensory research before product launch (van Kleef et al., 2005; Ryynänen and Hakatie, 2014). Therefore, additional measurements by consumers such as emotional and sensory profiling are gaining interest as a way to better understand consumers' motivations for food choice (Varela and Ares, 2012; Meiselman, 2013; Jiang et al., 2014).

When consumers perceive an object such as a food product or food brand, conceptual associations will be generated, triggering an emotional response that may be positively or negatively rewarding (Thomson, 2015). Conceptualizations can be broadly classified into 2 categories based upon their connotations: emotional or functional (Thomson et al., 2010). It is important to notice the clear distinction between emotional conceptualizations and emotions as this has implications both on the scientific level (research methodology) and industry level (product development and marketing). Although a clear scientific definition of emotion is lacking (Lane and Nadel, 2002; Thomson and Crocker, 2013; Köster and Mojet, 2015), the consensus is that an emotion is something short term experienced by a person, whereas emotional conceptualizations have more permanence (Thomson and Crocker, 2015). Further, conceptualizations are also more related to the object instead of the individual, whereas emotions are highly dependent on the mood of the individual (Thomson and Crocker, 2015).

In recent years, several tools have been developed and applied to conduct emotional profiling tasks with food products ranging from explicit self-report instruments to implicit methods such as autonomic measures of emotion (e.g., skin conductance, heart rate) and brain 
states (e.g., functional magnetic resonance imaging; Köster and Mojet, 2015). However, the major studies in food science have worked with self-report instruments (Gutjar et al., 2015a) such as the EsSense Profile (King and Meiselman, 2010), PrEmo (Gutjar et al., 2015b), best-worst scaling (Crocker and Thomson, 2014), bullseye (Thomson and Crocker, 2014), EmoSensory Wheel (Schouteten et al., 2015b), and EmoSemio (Spinelli et al., 2014). During a self-report consumer test, participants are instructed to indicate which emotional terms they are experiencing or associating when consuming a food product. The emotional lexicon can be either from a standard list (e.g., EsSense Profile; King and Meiselman, 2010) or a consumer-defined lexicon specific for the product category under study (Jiang et al., 2014). One could stipulate that these self-report methods are reflecting emotional conceptualizations rather than specific emotions (Köster and Mojet, 2015; Thomson and Crocker, 2015). The measurement of emotional conceptualizations has gained momentum as it provides additional information to discriminate between food products, even when overall acceptance is similar (King and Meiselman, 2010; Ng et al., 2013a) and to improve food choice prediction (Dalenberg et al., 2014; Gutjar et al., 2015a).

Next to emotional profiling, interest is growing in letting consumers perform the sensory profiling of food products to obtain a better understanding on how they experience the different sensory properties of food products (Valentin et al., 2012). Several new methodologies have been developed such as check-allthat-apply (CATA), rate-all-that-apply (RATA), Napping, and flash profiling (Varela and Ares, 2012; Ares et al., 2014b). These new tools make it possible to cost efficiently retrieve feedback regarding how consumers perceive several sensory modalities such as aroma, flavor, texture, and aftertaste (Varela and Ares, 2012). Although these methods need to be seen as an additional way to provide feedback next to traditional profiling with trained experts, several studies have shown that these tools have been successfully applied for describing and quantifying product differences (Valentin et al., 2012; Varela and Ares, 2012; Cruz et al., 2013; Reinbach et al., 2014).

Although the growing body of literature studying sensory and emotional profiling of food products, questions remain about the ecological validity (Schmuckler, 2001) of sensory research when conducting emotional and sensory profiling using blind-labeled product samples at a sensory facility (Jaeger et al., 2016). In the field of sensory research, 2 different research settings are widely used to obtain consumer data: central location tests (CLT) and home-use tests (HUT; Lawless and Heymann, 2010). The majority of the tests carried out in scientific and industry take place as a CLT where consumers are evaluating products in isolated sensory booths to control against panelist bias and confounding nonproduct influences (Bangcuyo et al., 2015). Research has found that, depending on the product category, the evaluation context could influence the overall acceptance of food products (Edwards et al., 2003; Boutrolle et al., 2007; Mouta et al., 2016). Also, an evoked context effect has been even reported when consumers evaluated which emotions they experience while imagining a specific consumption context at a CLT (Piqueras-Fiszman and Jaeger, 2014a,b,c). But the question remains to which extent a real difference in testing location influences the sensory and emotional profiling of consumers.

Next to the evaluation setting, the ecological validity also includes the materials that are used (Schmuckler, 2001). Food choice is influenced by intrinsic (sensory properties), extrinsic (e.g., price, brand, packaging size), and credence quality cues (e.g., organic production, fair trade; Oude Ophuis and Van Trijp, 1995). Although the sensory properties of a product are of utmost importance, it is also important to examine the influence of extrinsic and credence quality cues on the sensory and emotional evaluation of food products (Meiselman, 2013; Spinelli et al., 2015; Jaeger et al., 2016). This will not only help to better understand consumers' evaluation of food products, but it also mimics better a real situation compared with the traditional blind sensory evaluation. One of the most important extrinsic cues for food producers is the brand as it is used to distinguish with competitors' products (Di Monaco et al., 2004; Fernqvist and Ekelund, 2014). Although branding is not a factor that has received a lot of attention in the sensory and consumer science field (Spinelli et al., 2015), several studies have found that brand information might influence overall acceptance (Paasovaara et al., 2012; Cavanagh and Forestell, 2013; Gutjar et al., 2015a; Spinelli et al., 2015) and purchase intent (Torres-Moreno et al., 2012). But little is known on the effect of brand labels on the emotional and sensory profiling of food products as previous studies worked with whole packages (Ng et al., 2013b; Gutjar et al., 2015a; Spinelli et al., 2015).

Four main psychological theories have been put forward to explain the effects of disconfirmation, generated by differences between the expectations and actual product performance, on consumers' product perception (Deliza and MacFie, 1996). The assimilation (or cognitive dissonance) theory stipulates that consumers adjust their perception of the product to be in line with the expected performance to minimize the differences between the expected and actual performance. The contrast theory specifies that a person will magnify 
the discrepancy between the expected and perceived performance. The generalized negativity theory applies when products are always negatively evaluated because the expectations were not met. The assimilation/contrast theory takes the size of the discrepancy between the expected and experienced evaluation into account. When the discrepancy is relatively small, the assimilation/contrast theory stipulates that it is likely that an assimilation effect will occur. However, if the discrepancy between what was expected and experienced becomes too large, a contrast effect may be observed instead.

The objective of this study was 2-fold: examination of the influence of (1) research setting (CLT vs. HUT) and (2) brand information on the overall acceptance, sensory, and emotional profiling. Strawberry-flavored yogurt brand, both private and premium labeled products, were selected as the design stimuli. While emotional profiling is gaining momentum, it is still mainly applied using unhealthy snack products, which calls for research on products that are expected to evoke fewer emotions, such as dairy products (Jiang et al., 2014). Because increased yogurt consumption and production are attributed to the perceived health benefits of yogurt and its consumer appeal (Desai et al., 2013), yogurt has been selected as the product of interest for this study.

\section{MATERIALS AND METHODS}

\section{Participants}

A total of 99 adult subjects (45 males and 54 females with the mean age of $29 \mathrm{yr}$ ) participated in 3 sessions. Participants were recruited from a database containing volunteers for sensory and consumer research of Ghent University. Slightly more than half of the sample $(54.5 \%)$ were living in the countryside. Only product users were eligible, in line with previous research showing that emotional profiles of nonusers and users differed too much (King and Meiselman, 2010). Further exclusion criteria were based upon food allergies (milk and soy products) and intolerances (lactose intolerant). Participants did not receive a monetary compensation for their participation and were not informed about the objective of the study.

\section{Products}

All yogurt products were commercially available at the time of the study and bought in the local supermarkets. Private label brands of the 3 major retailers in Belgium (covering in total more than $65 \%$ of the sales) as well as 2 premium brands were included in
Table 1. Product information about the 5 test products used in this test with the product code, the product brand, and the product classification

\begin{tabular}{lll}
\hline $\begin{array}{l}\text { Product } \\
\text { classification }\end{array}$ & Product brand & Product code \\
\hline Premium & Pur Natur & P1 \\
Premium & Danone & P2 \\
Private label & 365 & PL1 \\
Private label & Everyday & PL2 \\
Private label & Carrefour & PL3 \\
\hline
\end{tabular}

this study. The number of samples was limited to 5 to reduce sensory satiation of the participants (Gutjar et al., 2015b). Further, only small product samples were provided (enough for 2 to 3 bites; Ares et al., 2014b; Gutjar et al., 2015b). Products were strawberryflavored yogurts, and information about the products is listed in Table 1.

\section{Emotional and Sensory Term Selection}

Emotional terms were determined by using a 2-step procedure as suggested by prior research on developing a consumer-defined emotional lexicon (Ng et al., 2013a). A consumer defined-lexicon has the advantage that it is more specific, which leads to more discriminating terms compared with the standardized emotional list (Jaeger et al., 2013a; Ng et al., 2013a; Kenney and Adhikari, 2016). Another benefit of consumer-defined lexicons is the exclusion of irrelevant terms, leading to a shorter response time and less consumer boredom and fatigue (Jaeger et al., 2013a; Chaya et al., 2015). Further, most standardized emotion lists such as the widely applied EsSense profile (King and Meiselman, 2010) often focus on either positively (e.g., happy, good) or negatively (e.g., bad, unpleasant surprised) valenced terms, they are less suitable to provide an overall view of the product performance (Köster and Mojet, 2015; Spinelli et al., 2015). During the first step, a group of 20 consumers evaluated yogurt samples during 3 conditions: blind, expected, and informed. Consumers were asked to point out emotional terms that are applicable when tasting the sample (blind/informed condition) and seeing the brand logo (expected condition) using the CATA method. The emotional terms during this first step were based upon prior research (Laros and Steenkamp, 2005; Desmet and Schifferstein, 2008; King and Meiselman, 2010), but consumers also had the possibility to add their own terms. Second, the researchers finalized the list using 2 criteria: (1) number of consumers selecting the emotional terms $(\geq 10 \%$ for negative terms and $\geq 15 \%$ for positive terms) and (2) ability of the emotional terms to discriminate between the dif- 
ferent samples (Ferrarini et al., 2010; Thomson et al., 2010; De Pelsmaeker et al., 2013; Manzocco et al., 2013; $\mathrm{Ng}$ et al., 2013a; Jiang et al., 2014). The final selection contained 18 emotional conceptualization terms, of which 8 positively valenced (contented, friendly, good, happy, interested, pleasant, pleasant surprised, satisfied), 8 negatively valenced (bored, disappointed, discontented, disgust, dissatisfied, frustrated, stressed), and 2 neutral terms (calm, steady). This classification was based upon previous scholarly papers (Laros and Steenkamp, 2005; King and Meiselman, 2010) and terms that were opposites to those found in the literature (e.g., contented $=$ positively valenced and therefore discontented $=$ negatively valenced) were also classified this way ( $\mathrm{Ng}$ et al., 2013b).

Sensory terms were selected using a similar approach. Consumers $(\mathrm{n}=20)$ checked the applicable sensory terms while evaluating yogurt samples during a blind, expected, and informed condition. This master list was based upon pilot work and previous research (Desai et al., 2013; Cruz et al., 2013; Ares et al., 2014b; Castura et al., 2016). In addition, consumers had the possibility to add sensory terms. Researchers made a final selection based upon the frequency of selection $(\geq 15 \%)$ and the ability to discriminate between different yogurt samples. The final list contained terms covering multiple sensory modalities (appearance, aroma, flavor, texture, and aftertaste) in line with previous research (Ares et al., 2014a; Jaeger et al., 2015; Schouteten et al., 2015a). The following sensory terms were used to characterize the yogurt samples: aftertaste, creamy, dark color, firm, fruity aroma, fruity flavor, homogeneous, liquid, milky flavor, off-flavor, smooth, sour, sweet, and thick.

\section{Consumer Test}

The experiment was carried out with separate groups of consumers (one for CLT and one for HUT). All participants took part in 3 test sessions (blind, expected, and informed) with an interval of $1 \mathrm{wk}$ in between each session. Participants only tasted the samples during the first and third session.

Consumer tests of the CLT tests took place in the sensory facilities of Ghent University using EyeQuestion 3.15.10 (Logic8 BV, Elst, the Netherlands). Products were served in plastic transparent cups at a temperature of $6^{\circ} \mathrm{C}$. Participants were instructed to eat a nonsalty cracker and drink some water between the evaluation of the different samples to rinse their mouth. The presentation order of the samples was randomized between the subjects.

Home-use tests took place in the same weeks of the CLT tests and computerized questionnaires (EyeQues- tion 3.15.10) were used. A researcher visited the participants at home twice. The first time, the researcher provided the necessary materials for conducting the tests. The consumers did not use the product over a period of time, to make the test similar to the laboratory test (Hersleth et al., 2005). Consumers were instructed to evaluate the product when they wanted and together with family, friends, or both, but they were instructed to personally consume a minimal amount as was also clearly mentioned on the computerized questionnaire (Boutrolle et al., 2007). Exactly 1 wk later, participants of the HUT received electronically a link to complete the questionnaire of the second session. Last, a researcher made a second visit to the participants to deliver the materials for the second session. The procedure for the sample evaluation was the same as for participants of the CLT test (e.g., randomized sample presentation order and palate cleansing).

During the first session (tasting), consumers first answered general questions about their yogurt consumption, shopping behavior, and private label brands (not included in this study). Participants tasted each product, and then first rated overall liking using a 9-point scale. They were instructed to take a second spoonful of the sample before completing the emotional and sensory profile task, which was based on the validated EmoSensory Wheel format (Schouteten et al., 2015b). Consumers were instructed to "tick on each word that applies to describe yogurt sample XXX and rate its intensity" for the sensory profiling task and to "rate the intensity of the words which describe how you feel right now" for the emotional profiling task. These are the same instructions as the validated EmoSensory Wheel (Schouteten et al., 2015b) and are similar to those used in other consumer studies for the sensory (Jaeger et al., 2013b) and emotional profiling (King and Meiselman, 2010) of food products.

The RATA approach (Ares et al., 2014b) was applied for the profiling using a 5-point scale with end-point anchors $(1=$ slightly to $5=$ extremely). Sensory and emotional terms were listed alphabetically to ease the consumer's response process and because previous research concluded that alphabetical order is not likely to bias the profiling results compared with a randomized order (Ares et al., 2013; King et al., 2013). Last, some socio-demographic questions were gathered (sex, age, place of living).

One week later, respondents participated in the second session (expected). They were presented with the brand logos of the selected samples in a randomized order. Participants were first asked to express their expected overall liking of a strawberry-flavored yogurt from the projected brand. Next, they assessed which 
emotions they associate with that brand logo and to which extent they expect the presence of the sensory properties for yogurt of the projected brand.

The third session (tasting + informed) had the same structure as the second session, but consumers actually tasted the yogurt products during this informed condition. Consumers were presented with the brand logos, in a randomized order, accompanied by the yogurt sample. They first assessed their overall liking and then conducted the EmoSensory profiling of each product sample.

\section{Data Analysis}

Analysis of variance (factors: samples and location) was performed separately on the blind, expected, and informed liking scores to determine to which extent liking scores differed between the locations for each condition (Boutrolle et al., 2005).

The procedure for data analysis of sensory and emotional terms was similar. Two approaches were used to analyses RATA data: (1) frequency of selection only or (2) weighted frequency of selection (i.e., by assigning the points of the scale to numbers in increasing order corresponding to the perceived intensity; RATA scoring; Ares et al., 2014b). This makes it possible to calculating the scores for each term of sample by summing up the scores provided by consumers who selected that term. Also, a recent study conducted by Meyners et al. (2016) suggests that a missing check can be interpreted as a 0 , interpreting the obtained RATA data in this study as 6-point scales.

Further, the emotional and sensory profiles between the locations were compared regarding (1) term usage and (2) sample differences configurations for each condition (blind/expected/informed) separately (Ares et al., 2014b). Differences regarding the sample configurations were also included for the sensory profiling but not for the emotional profiling given the low number of samples differing in emotional terms. Fisher's exact test was used to determine significant differences in the total number of terms used between the 2 experimental conditions (CLT and HUT) by participants to describe the whole sample set. Cochran's Q test was carried out to determine significant differences of the frequency of term selection between conditions, and Friedman's test was carried out to identify significant differences for terms between samples taking the weighted frequency of selection into account. Lastly, correspondence analysis (CA) was performed on both the frequency table containing the number of participants who used each term for describing each sample (RATA) and on the sum of scores given by all participants to each term for describing the intensity of the applicable term (RATA scoring). Correspondence analysis, using Hellinger's distances as recommended by Meyners et al. (2013), was carried out for each experimental treatment comparing for each condition separately. The similarity between the sample and term configurations in the first 2 dimensions obtained from the CA was compared between the conditions using the RV coefficient for each condition separately.

For each location (CLT/HUT) and type of terms (emotional conceptualization/sensory attribute), significant differences in frequency of selection of each term between the yogurt samples were determined by applying Cochran's Q test for each condition. If significant differences were found, pairwise comparison between the products for each term during a specific condition was performed using the McNemar test.

Two-way ANOVA (factors: subject and samples) and Fisher's least significant difference post hoc tests were independently applied to the blind, expected, and informed liking scores to determine product differences. Student $t$-tests were carried out to detect differences between expected and blind $(\mathrm{E}-\mathrm{B})$, informed and blind $(\mathrm{I}-\mathrm{B})$, and informed and expected ( $\mathrm{I}-\mathrm{E})$ liking scores following $\mathrm{Ng}$ et al. (2013b) and Spinelli et al. (2015).

Repeated measures ANOVA with product presentation condition (3 levels: blind, expected, and informed) and product (5 levels: product A-E) as within-subject factors were carried out to test for significant differences in term scores (dependent variable) for each product independently for each location (CLT/HUT; Gutjar et al., 2015a). This test was performed for each of the 18 emotional and 14 sensory terms separately. Post hoc pairwise comparisons with Bonferroni correction were carried out between the different conditions.

Biplots were used to examine the associations between the sensory attributes and the samples for each condition and location independently.

\section{RESULTS}

\section{Effect of Research Setting}

Overall Liking. First of all, the extent to which the research setting affected the overall liking was analyzed under the 3 different conditions separately. When consumers evaluated the samples under blind or expected condition, no effect of the research setting on the overall liking scores was found (Table 2). A significant effect of the interaction between samples and setting on the overall liking scores was found under the informed condition, indicating that the influence of the 
Table 2. Two-way analyses of variance $(\mathrm{n}=99)$ with interactions for sample and location data for each of the conditions separately

\begin{tabular}{llrrr}
\hline Condition & Source & $F$ & df & $P$-value \\
\hline Blind & Sample & 3.587 & 4 & 0.007 \\
& Setting & 0.031 & 1 & 0.861 \\
\multirow{3}{*}{ Expected } & Sample $\times$ setting & 1.586 & 4 & 0.177 \\
& Sample & 31.206 & 4 & $<0.001$ \\
& Location & 0.006 & 1 & 0.938 \\
& Sample $\times$ setting & 0.240 & 4 & 0.916 \\
& Sample & 2.213 & 4 & 0.067 \\
& Setting $\times$ setting & 2.906 & 1 & 0.089 \\
& Sample $\times$ s. & 2.618 & 4 & 0.034 \\
\hline
\end{tabular}

location was not the same for all samples. Simple main effects were calculated and showed a significant effect of the location on the informed liking scores of samples P1 and PL2. The informed liking of both samples was higher when evaluated in the laboratory environment compared with the home environment.

Emotional Profiling. Participants who conducted the profiling task in the CLT used a significantly larger number of emotional terms compared with users who performed the task at home during the expected and informed conditions. No differences in the frequency of term use were found under the blind condition (Table $3)$.

More emotional terms with significant differences among samples were found when the test was carried out in a laboratory setting (Table 3 ). Also, more significant differences were found when taking the scores into account (RATA scoring).

Sensory Profiling. Participants selected more terms for the sensory profiling tasks during the blind and informed condition compared with the expected condition, regardless of the location of the task. Further, participants who performed the test at the laboratory tended to use more sensory terms than those who executed the test at home during the expected and informed conditions. However, similar to the frequency of emotional terms, it was the other way around under the blind condition where consumers at home tended to use more sensory terms for the sensory profiling task (Table 4).

Although the discriminatory capability of the sensory terms was highly similar under the informed condition, this was less the case under the blind and expected condition (Table 4). Also, similar to the results of the emotional profiling, the discriminatory capability tended to be a bit higher when the intensity scores were taken into account.

Percentage of variance explained by the first 2 dimensions of the CA was higher than $70 \%$ in each case (Table 4). All the RV coefficients obtained by comparing the sample configurations between the sensory

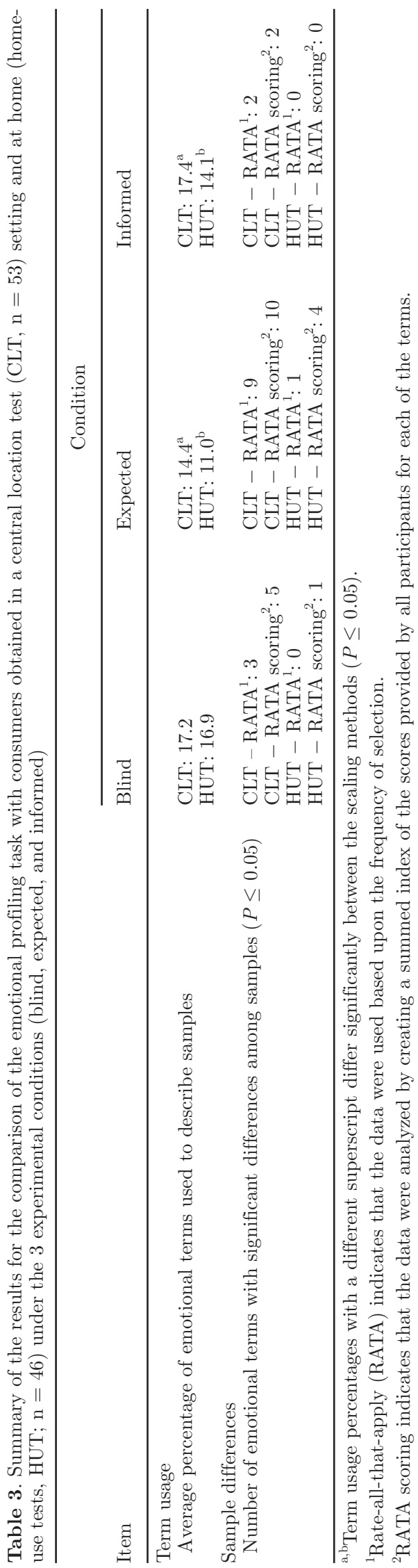

Journal of Dairy Science Vol. 100 No. 1, 2017 
CONTEXT AND BRAND EFFECT ON YOGURT EVALUATION

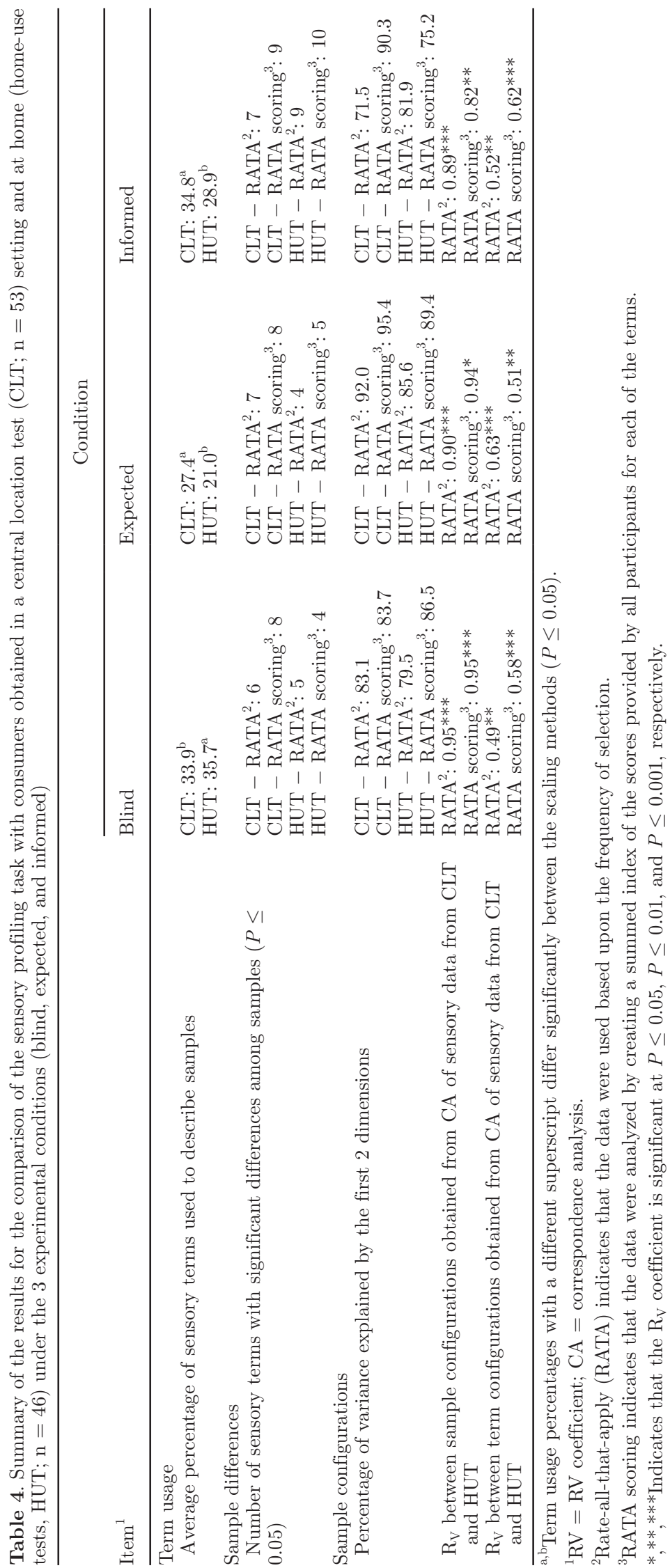


profiles of the both research settings were significant, and high values were obtained as the lowest RV score was 0.82 . Although the RV coefficients were lower for the term configurations compared with the product configurations, all RV coefficients were significant.

\section{Effect of Brand}

Overall Liking. Significant differences were found in consumers' overall liking for the products under blind $[\mathrm{F}(208,4)=5.100, P \leq 0.001]$ and expected conditions $[\mathrm{F}(208,4)=26.984, P \leq 0.001]$ at the CLT (Table 5). During the blind condition, private-label product PL2 was the most liked whereas products P1 and PL1 were the least liked. However, in the expected condition, product P2 (premium brand) was significantly most liked, whereas no significant differences were found in terms of overall liking between the samples in the informed condition $[\mathrm{F}(208,4)=0.662, P=0.619$; Table $5]$. Results of the paired $t$-tests showed that the expected liking of the yogurt samples of the 2 premium brands was significantly higher compared with the blind assessment, illustrating a negative disconfirmation effect. In contrast, overall liking of product PL2 was significantly higher during the blind condition than the expected condition. This shows that providing brand information can lead to higher expected liking scores, albeit depending on the sample. The informed scores were generally close to the blind liking scores, suggesting that the overall liking was mainly sensory driven. However, for product P1, a complete assimilation effect occurred as informed liking was closer to the expected liking compared with the blind liking. This illustrates that for product P1, a premium brand, mentioning the brand logo has a significant effect on the overall liking.

During the HUT, significant differences in the overall liking were only present during the expected $[\mathrm{F}(180,4)$ $=17.186, P \leq 0.001]$ and informed condition $[\mathrm{F}(180,4)$ $=4.091, P=0.003]$. The overall liking of premium brand PL2 was the highest during the expected condition, which was also the case in the CLT test. Participants of the HUT gave the highest informed overall liking scores to samples PL1 and P2. It is interesting that no significant differences in terms of overall liking were found during the blind condition $[\mathrm{F}(180,4)$ $=0.898, P=0.466]$. Expected liking scores was significantly higher than the blind liking scores for the 2 premium brand samples when participants evaluated the samples at home. No significant differences were found between the informed and blind overall liking of any sample, indicating that the overall liking was little influenced by the brand information during the HUT. Further, informed liking scores were significantly lower compared with the expected scores for both premium brands. Although consumers have high expectations for both premium branded products, they are apparently not able to fulfil these expectations, which led to an informed liking score comparable to those obtained during the blind evaluation of the yogurt products.

Emotional Profiling Across Conditions. The frequencies of the discriminating emotional terms for each condition during the CLT are listed in Table 6. It is interesting that no emotional conceptualization was discriminating between the 5 samples under all 3 conditions. Under the blind condition, only 3 (unpleasant surprised, frustrated, and disgust) out of 18

Table 5. Blind (B), expected (E), and informed (I) mean (SD) liking scores of products evaluated under blind, expected (brand logo), and informed conditions by consumers (on a 9-point scale) at the central location tests (CLT; $\mathrm{n}=53$ ) and home-use tests (HUT; $\mathrm{n}=46$ ), together with differences between mean ratings for each sample ${ }^{1}$

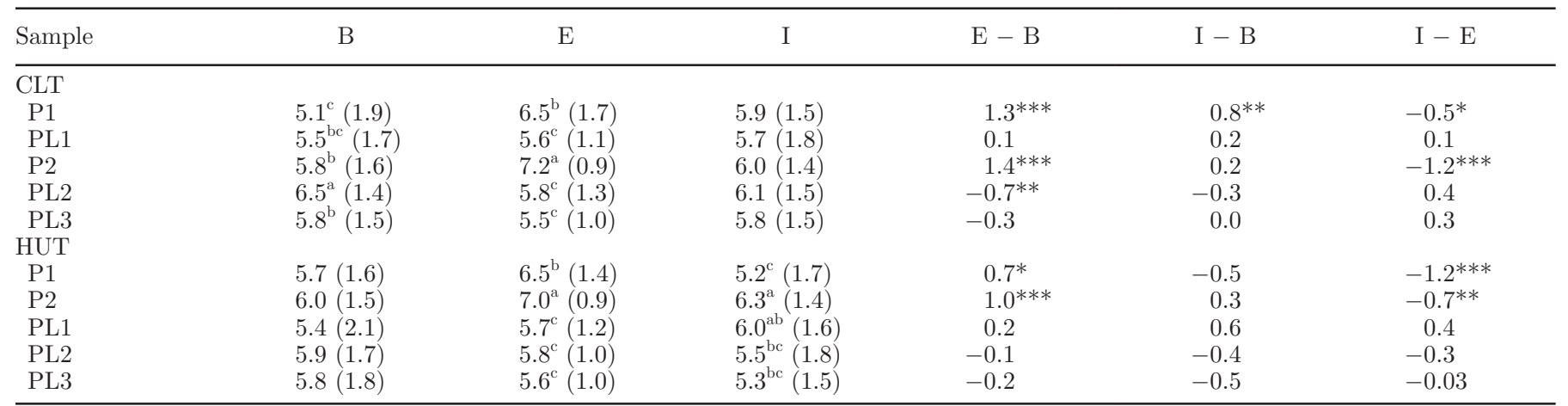

${ }^{\mathrm{a}-\mathrm{c}}$ Products with the same superscript, within a column, are not significantly different $(P \leq 0.05)$ during the condition (blind/expected/informed).

${ }^{1} \mathrm{E}$ - B denotes expected minus blind liking scores; I - B denotes informed minus blind liking scores; I - E denotes informed minus expected liking scores. P1 and P2 are premium product codes; PL1, PL2, and PL3 are private label codes.

$*, * *, * * *$ Depicts significant differences between the liking scores at $P \leq 0.05, P \leq 0.01$, and $P \leq 0.001$, respectively. 
Table 6. Frequency count of the discriminating emotional terms under the different conditions at the central location tests (CLT) for each sample ${ }^{1}(\mathrm{n}=53)$

\begin{tabular}{|c|c|c|c|c|c|}
\hline Term & $\mathrm{P} 1$ & $\mathrm{P} 2$ & PL1 & PL2 & PL3 \\
\hline \multicolumn{6}{|l|}{ Blind } \\
\hline Disgust & $12^{\mathrm{a}}$ & $2^{\mathrm{b}}$ & $5^{\mathrm{ab}}$ & $1^{\mathrm{b}}$ & $3^{\mathrm{b}}$ \\
\hline Frustrated & $7^{\mathrm{a}}$ & $1^{\mathrm{b}}$ & $1^{\mathrm{ab}}$ & $2^{\mathrm{ab}}$ & $2^{\mathrm{ab}}$ \\
\hline Unpleasant surprised & $13^{\mathrm{ab}}$ & $8^{\mathrm{abc}}$ & $15^{\mathrm{a}}$ & $2^{\mathrm{c}}$ & $6^{\mathrm{bc}}$ \\
\hline \multicolumn{6}{|l|}{ Expected } \\
\hline Bored & $2^{\mathrm{ab}}$ & $1^{\mathrm{b}}$ & $8^{\mathrm{a}}$ & $3^{\mathrm{ab}}$ & $4^{\mathrm{ab}}$ \\
\hline Dissatisfied & $2^{\mathrm{ab}}$ & $1^{\mathrm{b}}$ & $6^{\mathrm{ab}}$ & $9^{\mathrm{a}}$ & $7^{\mathrm{ab}}$ \\
\hline Friendly & $17^{\mathrm{a}}$ & $11^{\mathrm{ab}}$ & $9^{\mathrm{ab}}$ & $7^{\mathrm{b}}$ & $8^{\mathrm{b}}$ \\
\hline Good & $21^{\mathrm{bc}}$ & $32^{\mathrm{a}}$ & $19^{\mathrm{bc}}$ & $26^{\mathrm{ab}}$ & $17^{\mathrm{c}}$ \\
\hline Happy & $13^{\mathrm{ab}}$ & $16^{\mathrm{a}}$ & $5^{\mathrm{c}}$ & $6^{\mathrm{bc}}$ & $7^{\mathrm{bc}}$ \\
\hline Interested & $5^{\mathrm{ab}}$ & $3^{\mathrm{b}}$ & $11^{\mathrm{a}}$ & $3^{\mathrm{b}}$ & $3^{\mathrm{b}}$ \\
\hline Pleasant & $18^{\mathrm{ab}}$ & $22^{\mathrm{a}}$ & $8^{\mathrm{c}}$ & $10^{\mathrm{bc}}$ & $9^{\mathrm{bc}}$ \\
\hline Satisfied & $15^{\mathrm{a}}$ & $20^{\mathrm{a}}$ & $6^{\mathrm{b}}$ & $12^{\mathrm{ab}}$ & $9^{\mathrm{b}}$ \\
\hline Steady & $17^{\mathrm{a}}$ & $10^{\mathrm{ab}}$ & $4^{\mathrm{b}}$ & $10^{\mathrm{ab}}$ & $6^{\mathrm{b}}$ \\
\hline \multicolumn{6}{|l|}{ Informed } \\
\hline Pleasant surprised & $10^{\mathrm{ab}}$ & $4^{\mathrm{b}}$ & $12^{\mathrm{ab}}$ & $15^{\mathrm{a}}$ & $15^{\mathrm{a}}$ \\
\hline Steady & $16^{\mathrm{a}}$ & $6^{\mathrm{bc}}$ & $11^{\mathrm{ab}}$ & $12^{\mathrm{ab}}$ & $2^{\mathrm{c}}$ \\
\hline
\end{tabular}

${ }^{a-c}$ Frequencies with the same superscript, within a row, are not significantly different $(P \leq 0.05)$.

${ }^{1} \mathrm{P} 1$ and $\mathrm{P} 2$ are premium product codes; PL1, PL2, and PL3 are private label codes.

emotional terms were discriminative and those 3 terms were all negatively valenced. More consumers used those negatively valenced terms for sample P1 compared with sample P2 and PL2. Half of the emotional conceptualizations terms were discriminative among the samples under the expected condition and those discriminating terms were mainly positively valenced. In general, yogurts of the premium brands P1 and P2 were associated with the positive terms and less to the negatively valenced terms by more participants compared with the other 3 private label brands under the expected condition. Only 2 emotional terms, namely "steady" and "pleasant surprised," were discriminating between the products under the informed condition. More participants associated "pleasant surprised" with the PL2 and PL3 compared with the premium sample P2. Further, more participants found yogurt P1 "steady" compared with the other premium brand P2 and also private label sample PL3.

When checking for significant differences in the number of participants checking an emotional term between the samples under a certain condition at the HUT, the statistical test revealed few differences. A significant difference was only found for the term "pleasant" under the expected condition; more consumers used the term "pleasant" for sample P2 (15 consumers) compared with samples PL1 and PL2 (both samples: 5 consumers).

Next to the frequency of use, the effect of brand information on the intensity of emotional conceptualizations for the same product was examined. The rating of the emotional terms differed between the conditions for the CLT mainly for product P1 with differences for 6 emotional terms (Table 7). When comparing the blind and informed conditions, it is clear that the brand information had rather little influence on the emotional profiling of the samples during the CLT. A significant effect of the brand information on the emotional conceptualizations was only found for the terms "pleasant" and "pleasant surprised" of product PL3. Also for the HUT, little influence of brand information on the intensity of emotional ratings was found as only the intensity of the emotional conceptualization "pleasant" was significantly higher rated for PL3 when participants were informed about the brand. Furthermore, the significant differences in ratings between the conditions were all in the same direction as the HUT for the different brands: the intensity ratings of the emotional terms were lower during the expected condition compared with the blind and informed conditions.

Sensory Profiling Across Conditions. Of the 14 sensory terms listed in the EmoSensory Wheel, 11 presented significant differences between the samples under at least condition for the CLT. Differences in usage frequency between the samples for the terms "homogeneous," "sour," and "liquid" occurred during each condition, indicating that these are very discriminating between the samples. As at least the usage frequency of 6 sensory terms differed significantly under each condition, this shows that consumers perceived differences in the sensory characteristics of the yogurts under each condition at the CLT (Table 8).

Although the usage frequency of 13 out of 14 sensory terms was significantly different when participants evaluated the samples at home, perceived differences 
Table 7. Mean emotional ratings per product under the 3 conditions $(\mathrm{B}=$ blind, $\mathrm{E}=$ expected, and $\mathrm{I}=$ informed $)$ in the central location tests (CLT; $\mathrm{n}=53)$ and home-use tests (HUT; $\mathrm{n}=46)^{1}$

\begin{tabular}{|c|c|c|c|c|c|c|c|c|c|c|c|c|c|}
\hline \multirow[b]{2}{*}{ Item } & \multicolumn{6}{|c|}{ CLT } & \multirow[b]{2}{*}{ Item } & \multicolumn{6}{|c|}{ HUT } \\
\hline & B & $E-B$ & $\mathrm{E}$ & $\mathrm{I}-\mathrm{E}$ & I & $\mathrm{I}-\mathrm{B}$ & & B & $E-B$ & $\mathrm{E}$ & $\mathrm{I}-\mathrm{E}$ & I & $\mathrm{I}-\mathrm{B}$ \\
\hline Disappointed & $1.21^{\mathrm{a}}$ & $\downarrow$ & $0.38^{\mathrm{b}}$ & & $0.66^{\mathrm{ab}}$ & & Disappointed & $0.37^{\mathrm{ab}}$ & & $0.07^{\mathrm{b}}$ & $\uparrow$ & $0.98^{\mathrm{a}}$ & \\
\hline Discontented & $1.06^{\mathrm{a}}$ & $\downarrow$ & $0.04^{\mathrm{b}}$ & $\uparrow$ & $0.51^{\mathrm{a}}$ & & Dissatisfied & $0.43^{\mathrm{a}}$ & $\downarrow$ & $0.00^{\mathrm{b}}$ & $\uparrow$ & $0.74^{\mathrm{a}}$ & \\
\hline Disgust & $0.58^{\mathrm{a}}$ & $\downarrow$ & $0.00^{\mathrm{b}}$ & & $0.26^{\mathrm{ab}}$ & & Pleasant surprised & $0.35^{\mathrm{ab}}$ & & $0.07^{\mathrm{b}}$ & $\uparrow$ & $0.61^{\mathrm{a}}$ & \\
\hline Friendly & $0.19^{\mathrm{b}}$ & $\uparrow$ & $1.09^{\mathrm{a}}$ & & $0.70^{\mathrm{ab}}$ & & & & & & & & \\
\hline P2 & & & & & & & P2 & & & & & & \\
\hline Disappointed & $0.70^{\mathrm{a}}$ & $\downarrow$ & $0.09^{\mathrm{b}}$ & $\uparrow$ & $0.58^{\mathrm{a}}$ & & Disappointed & $0.33^{\mathrm{ab}}$ & & $0.07^{\mathrm{b}}$ & $\uparrow$ & $0.61^{\mathrm{a}}$ & \\
\hline Good & $0.85^{\mathrm{b}}$ & $\uparrow$ & $2.08^{\mathrm{a}}$ & $\downarrow$ & $0.87^{\mathrm{b}}$ & & & & & & & & \\
\hline Unpleasant surprised & $0.40^{\mathrm{ab}}$ & & $0.04^{\mathrm{b}}$ & $\uparrow$ & $0.66^{\mathrm{a}}$ & & & & & & & & \\
\hline PL1 & & & & & & & PL1 & & & & & & \\
\hline Bored & $0.09^{\mathrm{ab}}$ & & $0.53^{\mathrm{a}}$ & $\downarrow$ & $0.04^{\mathrm{b}}$ & & Disappointed & $1.02^{\mathrm{a}}$ & $\downarrow$ & $0.22^{\mathrm{b}}$ & & $0.39^{\mathrm{ab}}$ & \\
\hline Disappointed & $0.89^{\mathrm{a}}$ & $\downarrow$ & $0.23^{\mathrm{b}}$ & & $0.68^{\mathrm{ab}}$ & & Disgust & $0.52^{\mathrm{a}}$ & $\downarrow$ & $0.00^{\mathrm{b}}$ & & $0.13^{\mathrm{ab}}$ & \\
\hline Pleasant surprised & $0.87^{\mathrm{a}}$ & $\downarrow$ & $0.32^{\mathrm{b}}$ & $\uparrow$ & $1.00^{\mathrm{a}}$ & & Pleasant surprised & $0.87^{\mathrm{a}}$ & $\downarrow$ & $0.11^{\mathrm{b}}$ & & $0.37^{\mathrm{ab}}$ & \\
\hline PL3 & & & & & & & PL3 & & & & & & \\
\hline Pleasant & $0.92^{\mathrm{a}}$ & & $0.47^{\mathrm{ab}}$ & & $0.34^{\mathrm{b}}$ & $\downarrow$ & Interested & $0.80^{\mathrm{a}}$ & $\downarrow$ & $0.15^{\mathrm{b}}$ & & $0.24^{\mathrm{ab}}$ & \\
\hline Pleasant surprised & $0.43^{\mathrm{b}}$ & & $0.11^{\mathrm{b}}$ & $\uparrow$ & $0.96^{\mathrm{a}}$ & $\uparrow$ & Pleasant & $1.13^{\mathrm{a}}$ & & $0.41^{\mathrm{ab}}$ & & $0.30^{\mathrm{b}}$ & $\downarrow$ \\
\hline & & & & & & & Pleasant surprised & $0.98^{\mathrm{a}}$ & $\downarrow$ & $0.20^{\mathrm{b}}$ & & $0.52^{\mathrm{ab}}$ & \\
\hline & & & & & & & Satisfied & $1.80^{\mathrm{a}}$ & $\downarrow$ & $0.89^{\mathrm{b}}$ & & $0.76^{\mathrm{b}}$ & $\downarrow$ \\
\hline
\end{tabular}

\footnotetext{
${ }^{\mathrm{a}, \mathrm{b}}$ Intensities with the same superscript, within a row for a specific setting (CLT/HUT), are not significantly different $(P \leq 0.05)$.

${ }^{1}$ Directions of significant main effects are indicated by arrows $(P \leq 0.05)$. Only the emotional conceptualizations with ratings that differed significantly between conditions are presented. P1 and P2 are premium product codes; PL1, PL2, and PL3 are private label codes.
}

in the sensory characteristics between the samples occurred mainly under the informed condition (9 terms). This suggests that brand information influences the sensory profiles of the yogurt products (Table 8).

In total, the intensity rating of 12 sensory terms differed between the 3 conditions for the same product at the CLT: aftertaste, creamy, dark color, firm, fruity flavor, homogeneous, liquid, milky flavor, smooth, sour, sweet, and thick. Significant differences between the conditions for the sensory terms were especially found for the premium sample P2 of which a main effect of condition was found for 8 terms. In contrast, condition had little influence on the sensory profiling of the other premium sample P1 (Table 9).

Exploring the intensity of sensory terms that differentiate between the 3 conditions for the same product for the HUT, the statistical tests revealed significant main effects of the condition for 12 out of 14 sensory terms (aftertaste, creamy, firm, fruity aroma, homogeneous, liquid, milky flavor, off-flavor, smooth, sour, sweet, and thick). The number of sensory terms of which the intensity differed between the conditions ranged from 5 (P1, P2, and PL1) to 7 terms (PL3) for the samples (Table 9). Whereas brand information had little effect on the perceived intensity of sensory attributes of the samples when participants evaluated the samples at the laboratory, brand information influenced the sensory perception of at least one sensory attribute for 4 out of 5 samples (P1, P2, PL2, and PL3) when consumers were conducting the profiling task at home.

Biplots showed that the intensities of sensory attributes associated with the samples differed between the conditions. Figure 1a,b,c provides the biplot of the sensory attributes for the CLT test under the blind, expected, and informed conditions, respectively. Whereas different samples are scattered around the biplot under the blind condition (Figure 1a), the 3 private label samples are more grouped together under the expected condition (Figure 1b). When participants tasted the samples with product information, the biplot shows that both PL1 and PL2 samples are rather closely linked with similar sensory attributes such as creamy, sweet, fruity aroma, and fruity flavor. These 2 yogurt samples of a private label brand are also stronger linked with the premium sample P1 than the other private label sample PL3. The RV coefficients indicated that the configuration of the informed condition is more similar to the expected condition $(\mathrm{RV}=0.721, P=0.250$ ) 
than the informed condition $(\mathrm{RV}=0.688, P=0.433$ ) during the CLT test. When comparing the biplots of the HUT (Figure 2a,b,c), the differences between the blind condition on the one hand (Figure 2a) and the expected (Figure 2b) and informed (Figure 2c) conditions on the other hand are more pronounced. This is also reflected in the $R_{V}$ scores, with a rather high resemblance between the informed and expected condition ( RV = $0.866, P<0.001)$ and low resemblance between the informed and blind conditions $(\mathrm{RV}=0.717, P=0.550$ ). Apparently, participants of the HUT are influenced to a higher extent by brand information than participants of a CLT when conducting the sensory profiling task.

\section{DISCUSSION}

This study examines the influence of test location and brand information on the overall liking, and sensory and emotional profiling of yogurt brands under 3 evaluation conditions. The results of this study revealed that both research setting and brand information influenced the overall liking, and sensory and emotional profiles.

The research setting only had an effect on the overall liking when consumers received brand information as the overall liking was higher at the CLT test for 2 samples under the informed conditions. Most previous studies indicated that the testing location influences the hedonic assessment (Hellemann et al., 1993; DaillantSpinnler and Issanchou, 1995; Kozlowska et al., 2003; Boutrolle et al., 2005), similarly as in willingness-topay research (De Steur et al., 2014), but some studies reported no differences (Pound et al., 2000; Hersleth et al., 2005). It is interesting to note that the overall liking scores for 2 samples was higher at the CLT than HUT, whereas the majority of the other studies reported frequently lower liking scores at the CLT test (Hellemann et al., 1993; Daillant-Spinnler and Issanchou, 1995; Kozlowska et al., 2003; Boutrolle et al., 2005). Although Boutrolle et al. (2007) suggested that the different results might be explained by the product type or the methodology of the study, this study indicates that one should also bear the evaluation condition (blind, expected, informed) in mind as a potential influence on the overall liking when comparing results obtained at different testing locations. Nevertheless, the differences for 2 samples (P1 and PL2), liking scores of most samples (P2, PL1, and PL3) did not differ between the HUT and CLT. Hersleth et al. (2005) list several possibilities why the overall liking scores of products might be similar although products are evaluated under a different context. One of the possibilities is the familiarity of the type of products, which is a factor that

Table 8. Frequency count of the discriminating sensory terms under the different conditions during the central location tests $($ CLT; $\mathrm{n}=53$ ) and home-use tests $(\mathrm{HUT} ; \mathrm{n}=46)^{1}$

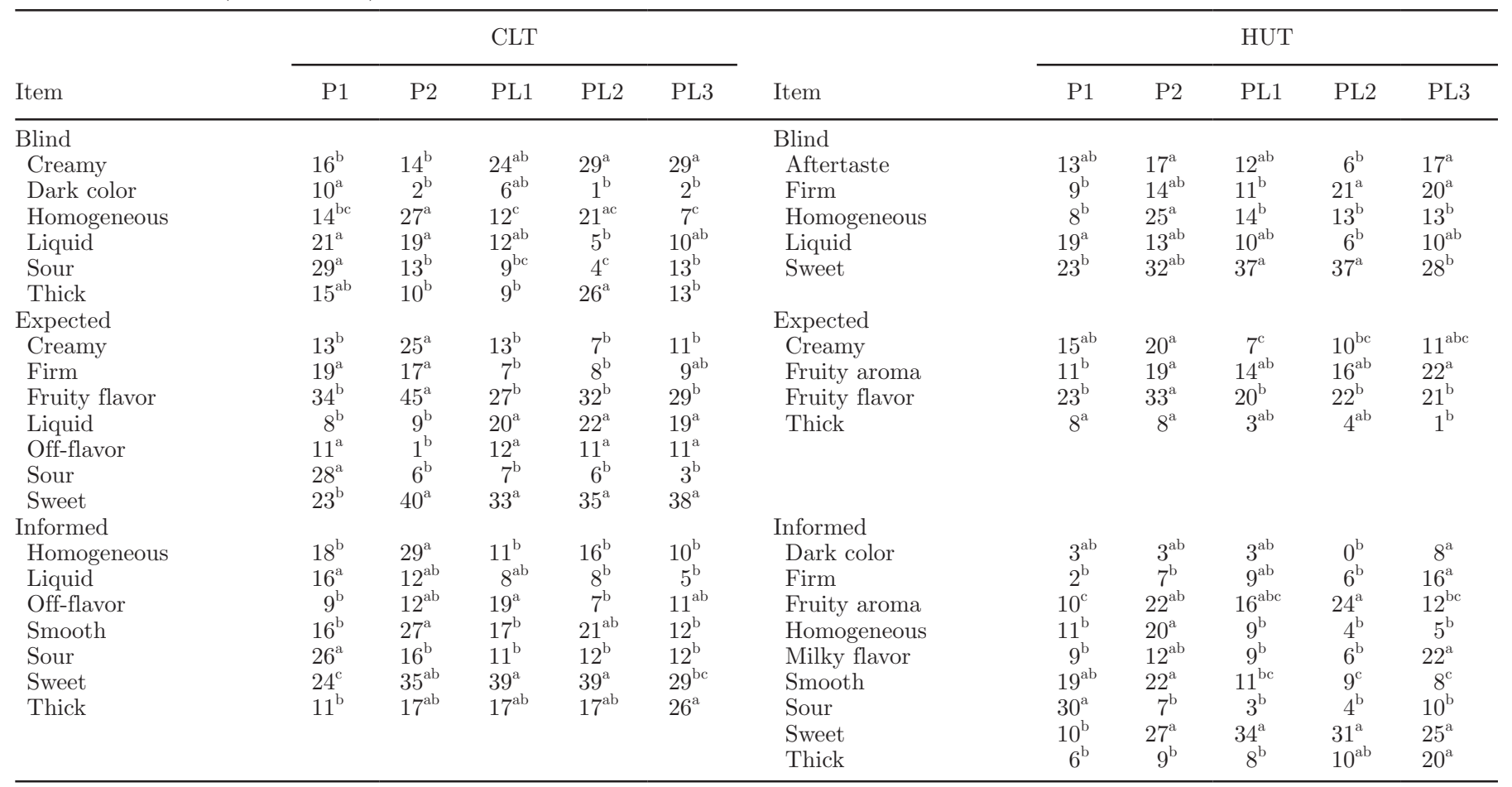

${ }^{\mathrm{a}-\mathrm{C}}$ Frequencies with the same superscript, within a row for a specific setting (CLT/HUT), are not significantly different $(P \leq 0.05)$.

${ }^{1} \mathrm{P} 1$ and $\mathrm{P} 2$ are premium product codes; PL1, PL2, and PL3 are private label codes. 
SCHOUTETEN ET AL.

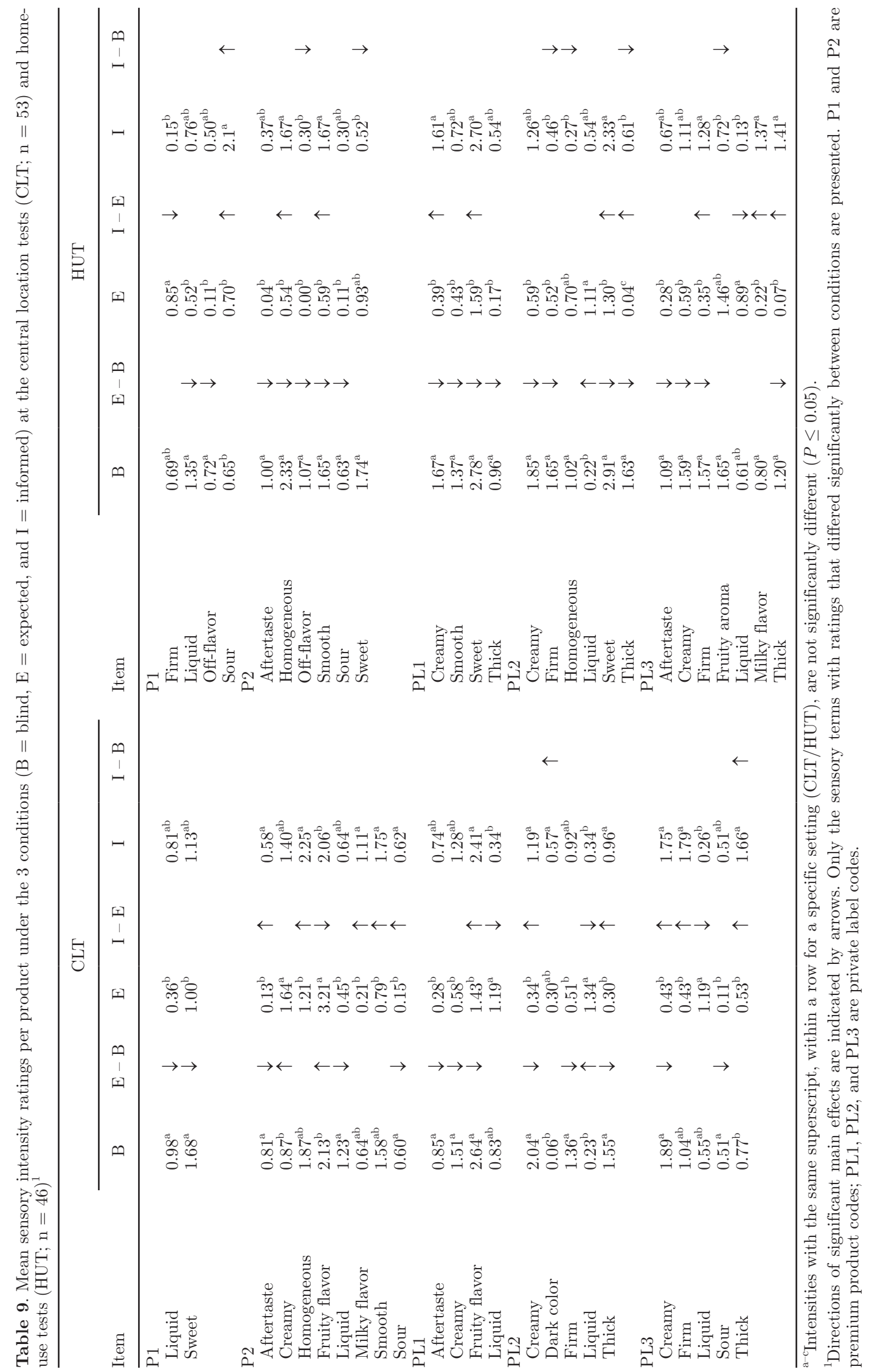


a. CIT - BLIND

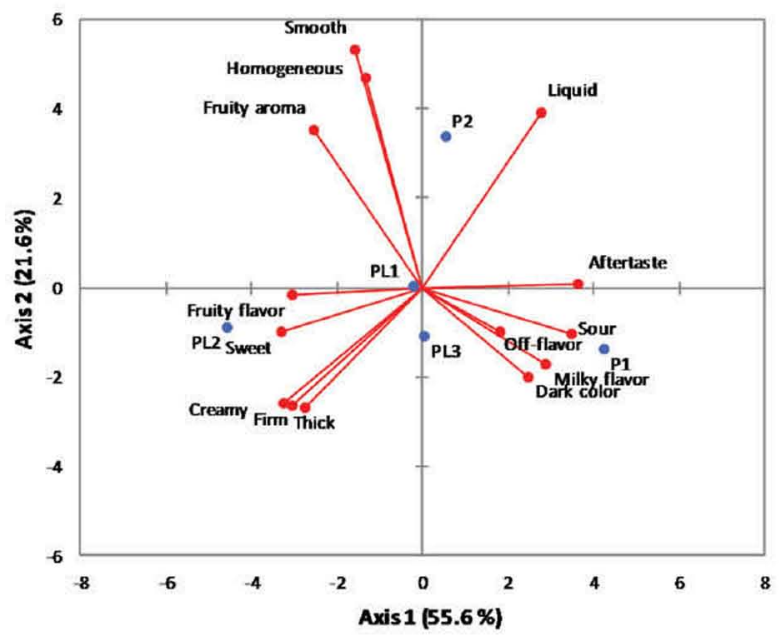

b. QIT - EXPECTED

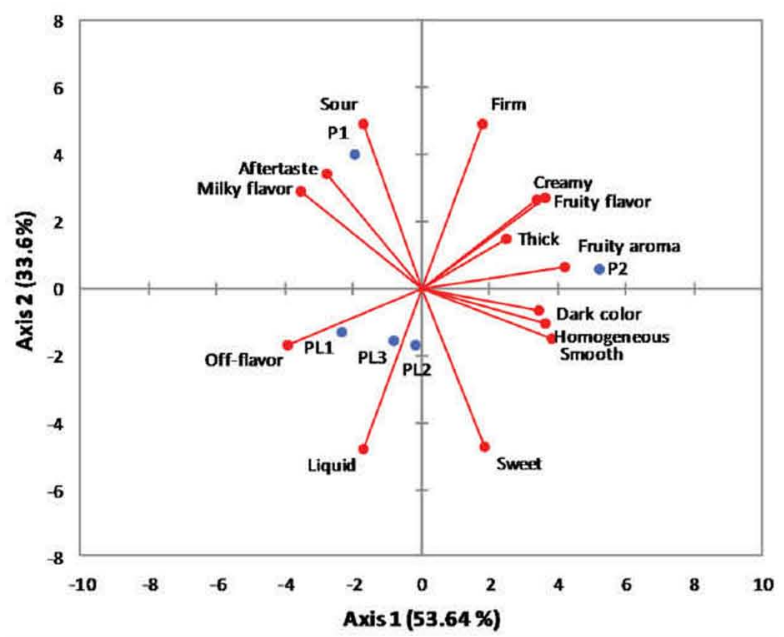

c. CLT - INFORMED

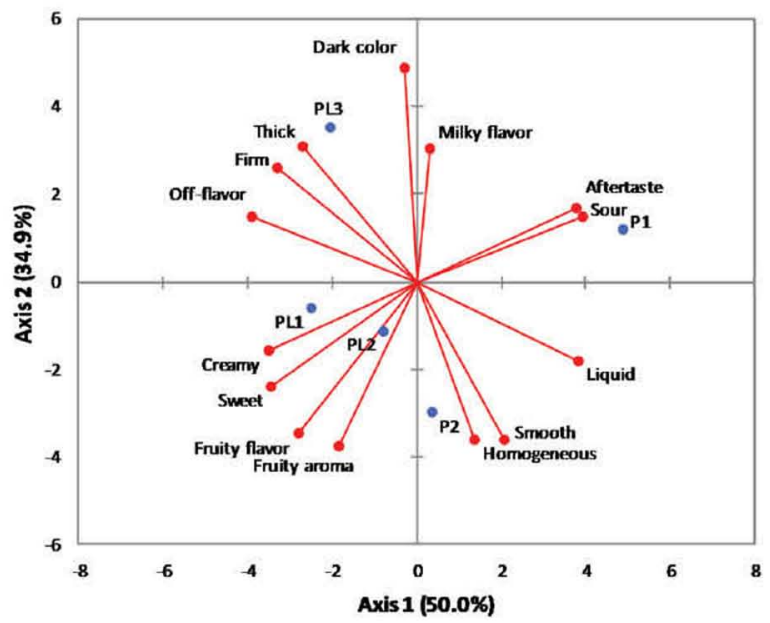

Figure 1. Biplots of the sensory profiles obtained at the central location tests (CLT) under the (a) blind, (b) expected, and (c) informed condition. P1 and P2 are premium product codes; PL1, PL2, and PL3 are private label codes. Color version available online.

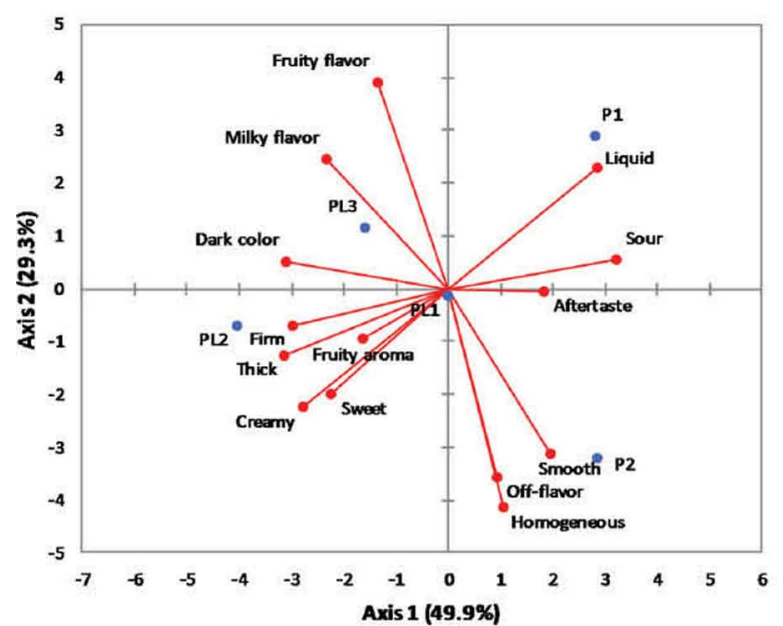

b. HUT- EXPECTED

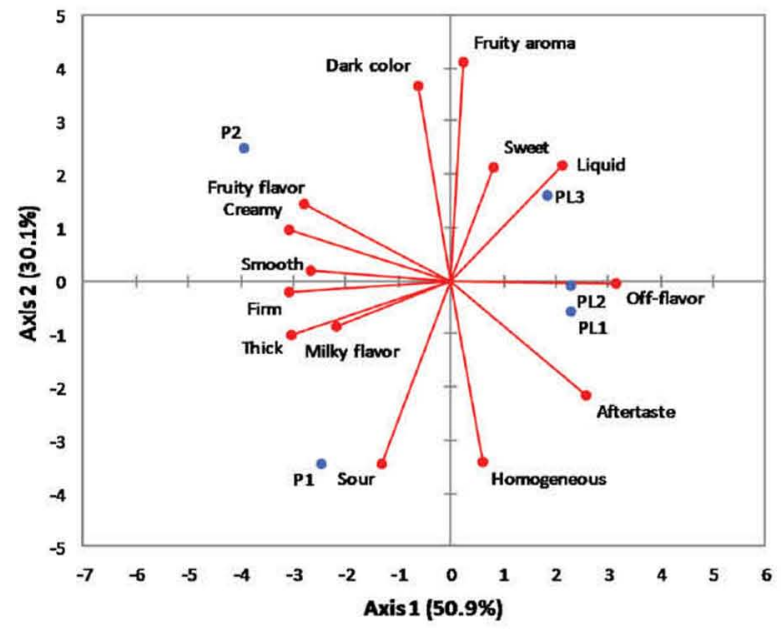

c. HUT - INFORMED

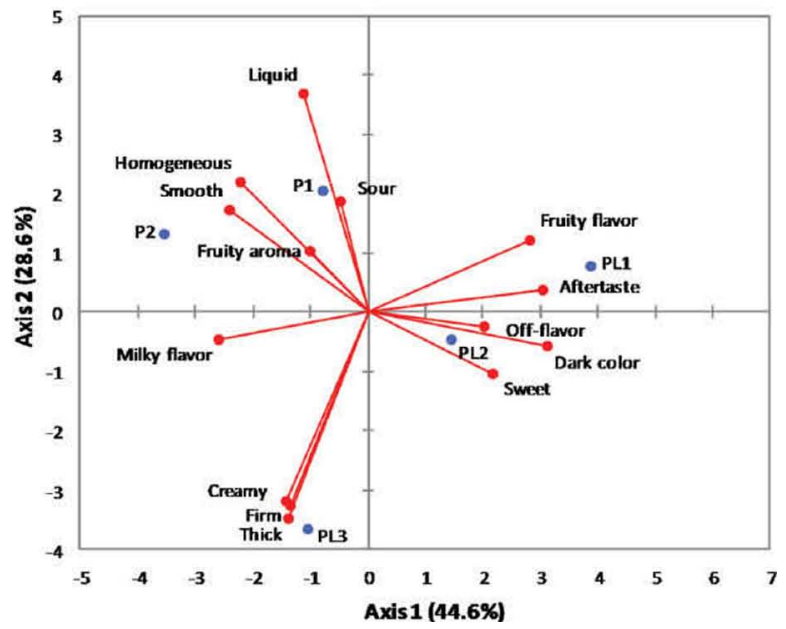

Figure 2. Biplots of the sensory profiles obtained at the home-use tests (HUT) under the (a) blind, (b) expected, and (c) informed condition. P1 and P2 are premium product codes; PL1, PL2, and PL3 are private label codes. Color version available online.

Journal of Dairy Science Vol. 100 No. 1, 2017 
should be considered because only yogurt product users were considered eligible for participating in this study. Furthermore, it is suggested that well-known and wellliked food products are less susceptible to the effect of changing contexts (King et al., 2007).

Only a small number of emotional terms were discriminating between both samples, which makes it hard to know if the research setting played a role in the discriminability of the emotional terms. The limited discriminative ability of the emotional terms might be the result of either the product category or the used samples as the average percentage of emotional terms used by consumers in this study was similar to those reported in other studies (King et al., 2013; PiquerasFiszman and Jaeger, 2014a). Danner et al. (2016) examined the influence of the 3 different contexts (home, laboratory, and restaurant context) on the emotional profiling of wine. This study found that participants associate more intensively positive emotions (e.g., happy, enthusiastic, adventurous) when evaluating wine samples at a restaurant compared with at home or in a laboratory environment. Few differences are reported in emotional profiling between the home and laboratory environment, which is in line with the findings of this study. Participants in the aforementioned wine study were all rather familiar with the product, just as in this study, which may have affected the results. Furthermore, several studies showed that the evoked context and appropriateness could influence the emotional profiling of food products (Piqueras-Fiszman and Jaeger, 2014b,c; Dorado et al., 2016).

Whereas the discriminability of the sensory terms was very similar under the blind and informed evaluation during the laboratory test, the informed condition yielded more differences in selected terms compared with the blind condition during the HUT. This suggests that the influence of the research setting on the performance of the sensory profiling task might depend on the evaluation condition. This study found similar term and sample configurations of the sensory profiling for both research settings, although one should note that most RV values were low. Therefore, more studies across different product categories and also different contexts (e.g., malls, imaginary context, or even virtual context) are necessary to confirm these findings.

This study also shows that premium brands generally generate higher scores for expected liking compared with the blind and informed conditions, indicating that extrinsic cues increase hedonic expectation. However, only an assimilation effect occurred for sample P1 when evaluated in the laboratory environment. As the informed liking scores tend to be closer by the blind liking scores than the expected liking scores, consumers' informed liking scores appeared to be primar- ily influenced by the sensory characteristics than the brand information regardless of whether the brand was premium label or private label. This is in contradiction with results of several other studies examining the influence of brand on the overall liking, which concluded that brand information influenced liking scores (Fernqvist and Ekelund, 2014). However, studies described in this review paper tended to work with whole packages, which was also the case for the only study involving yogurt products (Paasovaara et al., 2012). Therefore, it is not clear to what extent the brand influenced liking scores in the study of Paasovaara et al. (2012), because the type of image (Mizutani et al., 2010) or the package color (Piqueras-Fiszman and Spence, 2011) might influence overall liking.

Consumer's emotional conceptualizations were similar as liking scores, both at the CLT and HUT. For instance, when consumers' overall expected liking scores were higher compared with blind liking scores, this led to an increase in the rating scores of the positively valenced emotional conceptualizations and a decrease in the rating scores of the negatively valenced emotional conceptualizations. Few differences were found between the blind and informed emotion ratings, suggesting that emotional conceptualizations are mainly sensory driven, which is in line with previous research results (Ng et al., 2013b; Gutjar et al., 2015a; Schouteten et al., 2015a; Spinelli et al., 2015). Although brand information only played a secondary role on the emotional profiling, more systematic research is needed that involves other product categories.

Brand information also affected the sensory profiling of the samples, but this was mainly the case for the tests carried out at home. For instance, the intensity of the sweet taste of one of the premium brands (P1) was experienced as lower under the informed condition at home. This supports findings that information such as brand, content information, health information, and package could alter sensory perception (Cavanagh and Forestell, 2013; Stolzenbach et al., 2013; Vidal et al., 2013; Schouteten et al., 2015a, 2016). Further, results showed that the informed sensory profiling of the samples was more similar to the expected condition than the blind information. Although this was the case for both the HUT and CLT test, the similarity was more pronounced at the HUT. It might be that social interaction played a role (King et al., 2004) as consumers are tended to be more influenced by the brand information compared with the more individual evaluation at the CLT during this experiment.

The HUT is a more natural eating situation that differs from the controlled eating situation in the laboratory environment (CLT) in several ways, which could have affected the hedonic scores and emotional and 
sensory profiling. One potential factor is the time of the day. It is more likely that the time of consumption will be more appropriate for a consumer when he has the opportunity to choose it during a HUT then when the consumer needs to evaluate the sample at a fixed time during a CLT (Boutrolle et al., 2005). Time of consumption might not only influence the overall liking, but also affects the sensory profiling as the psychological state might be different, which could influence sensory perception. Related to this, the desire to eat the product is also expected to be higher during a HUT compared with CLT (Boutrolle et al., 2005, 2007), which might affect the emotional profiling task. Further, it has been suggested that a standardized CLT context could induce a more analytical mindset as it resembles a real experiment more than a test at home (Boutrolle et al., 2005). Consumers are also more likely to pay more attention during a CLT, which might explain the higher discrimination between the samples compared with the HUT found in this study. It is also possible that social interaction occurred at the HUT, whereas this is discouraged when evaluating products in separate booths at a CLT (Hersleth et al., 2005). Future research could ask for a description of the contextual factors to make a more thorough comparison possible of potential factors influencing the hedonic liking and emotional and sensory profiling of food products.

Consumers assessed their hedonic liking before conducting the EmoSensory Wheel task. Although this in line with research of King et al. (2013), it is unclear to what extent the hedonic liking might have influenced the profiling task. The present study worked with 5 samples, which is more than the 2 to 3 samples recommended in emotional research (King et al., 2013). However, the necessary precautions were undertaken in this study (e.g., small portion size, cleanse palate), and other studies have used a similar number of samples (Ng et al., 2013b; Gutjar et al., 2015a; Spinelli et al., 2015). Further, this study examined the differences between the context using a between-subjects design as applied in several other studies (Edwards et al., 2003; Boutrolle et al., 2005, 2007). However, one needs to bear this in mind when interpreting the results and future research could opt to work with a within-subject design to avoid potential inter-panel differences when examining context effects. Both emotional and sensory term lexicons used in this study were generated by consumers as suggested in previous research (Thomson, 2007; Ng et al., 2013a). In this study, we opted not to work with a standardized emotion questionnaire as these might contain too many items to ensure that no important terms are missed, which can have negative consequences on the collected data due to boredom and fatigue (Jaeger et al., 2013a; Ng et al., 2013a; Spinelli et al., 2015). Nevertheless, the question arises if the same conclusions could be drawn when, for instance, a standardized emotional list such as the EsSense Profile (King and Meiselman, 2010) or a sensory lexicon generated by expert panelists is used. Also, the terms in this study were scaled using the RATA approach (Ares et al., 2014b). Further research is needed with other scaling methods such as CATA and intensity scales to confirm the current findings. Although it is known how consumer attitudes (Villegas et al., 2008), frequency of use (King and Meiselman, 2010), and familiarity (Carrillo et al., 2012; Lahne et al., 2014) might play a role on the hedonic assessment and emotional and sensory profiling, further research is recommended on the extent to which such an effect might be influenced by the evaluation context. The technological advances also raise possibilities to break down the walls between the standardized (CLT) and more realistic setting. The use of immersive settings but also new material such as 3-D glasses raises possibilities for interesting future research (Bangcuyo et al., 2015; Jaeger et al., 2016).

In conclusion, both research setting and brand information may, under certain conditions, influence the sensory and emotional profiles of food products. The research setting mainly affects the emotional profiling of food products, whereas less effect was observed on the sensory profiling and overall liking. On the other hand, brand information mainly influenced the sensory profiling, whereas little effect was found on the emotional profiling and overall acceptance. Further, testing under the 3 evaluation conditions (blind, expected, and informed) can be important to obtain a better understanding of product performance. It makes it possible to detect, for instance, discrepancies in profiling under the different evaluation conditions, which can be of interest for the SensoEmotional optimization of food products (Thomson, 2007). As such, both researchers and industry should take into account potential effects when choosing the research setting and evaluation condition to increase the ecological validity and overall value of the findings for sensory and emotional profiling.

\section{ACKNOWLEDGMENTS}

Bram Bollaert is acknowledged for his help in the data collection.

\section{REFERENCES}

Ares, G., L. Antúnez, A. Giménez, C. M. Roigard, B. Pineau, D. C. Hunter, and S. R. Jaeger. 2014a. Further investigations into the reproducibility of check-all-that-apply (CATA) questions for sensory product characterization elicited by consumers. Food Qual. Prefer. 36:111-121. http://dx.doi.org/10.1016/j.foodqual.2014.03.010. 
Ares, G., F. Bruzzone, L. Vidal, R. S. Cadena, A. Giménez, B. Pineau, D. C. Hunter, A. G. Paisley, and S. R. Jaeger. 2014b. Evaluation of a rating-based variant of check-all-that-apply questions: Rate-allthat-apply (RATA). Food Qual. Prefer. 36:87-95. http://dx.doi. org/10.1016/j.foodqual.2014.03.006.

Ares, G., S. R. Jaeger, C. M. Bava, S. L. Chheang, D. Jin, A. Gimenez, L. Vidal, S. M. Fiszman, and P. Varela. 2013. CATA questions for sensory product characterization: Raising awareness of biases. Food Qual. Prefer. 30:114-127. http://dx.doi.org/10.1016/j. foodqual.2013.04.012.

Bangcuyo, R. G., K. J. Smith, J. L. Zumach, A. M. Pierce, G. A. Guttman, and C. T. Simons. 2015. The use of immersive technologies to improve consumer testing: The role of ecological validity, context and engagement in evaluating coffee. Food Qual. Prefer. 41:84-95. http://dx.doi.org/10.1016/j.foodqual.2014.11.017.

Boutrolle, I., D. Arranz, M. Rogeaux, and J. Delarue. 2005. Comparing central location test and home use test results: Application of a new criterion. Food Qual. Prefer. 16:704-713. http://dx.doi. org/10.1016/j.foodqual.2005.03.015.

Boutrolle, I., J. Delarue, D. Arranz, M. Rogeaux, and E. P. Köster. 2007. Central location test vs. home use test: Contrasting results depending on product type. Food Qual. Prefer. 18:490-499. http:// dx.doi.org/10.1016/j.foodqual.2006.06.003.

Carrillo, E., P. Varela, and S. Fiszman. 2012. Effects of food package information and sensory characteristics on the perception of healthiness and the acceptability of enriched biscuits. Food Res. Int. 48:209-216. http://dx.doi.org/10.1016/j.foodres.2012.03.016.

Castura, J. C., L. Antúnez, A. Giménez, and G. Ares. 2016. Temporal Check-All-That-Apply (TCATA): A novel dynamic method for characterizing products. Food Qual. Prefer. 47, Part A:79-90. http://dx.doi.org/10.1016/j.foodqual.2015.06.017.

Cavanagh, K. V., and C. A. Forestell. 2013. The effect of brand names on flavor perception and consumption in restrained and unrestrained eaters. Food Qual. Prefer. 28:505-509. http://dx.doi. org/10.1016/j.foodqual.2012.12.004.

Chaya, C., C. Eaton, L. Hewson, R. F. Vázquez, V. Fernández-Ruiz, K. A. Smart, and J. Hort. 2015. Developing a reduced consumerled lexicon to measure emotional response to beer. Food Qual. Prefer. 45:100-112. http://dx.doi.org/10.1016/j.foodqual.2015.06.003.

Crocker, C., and D. M. H. Thomson. 2014. Anchored scaling in best-worst experiments: A process for facilitating comparison of conceptual profiles. Food Qual. Prefer. 33:37-53. http://dx.doi. org/10.1016/j.foodqual.2013.11.005.

Cruz, A. G., R. S. Cadena, W. F. Castro, E. A. Esmerino, J. B. Rodrigues, L. Gaze, J. A. F. Faria, M. Q. Freitas, R. Deliza, and H. M. A. Bolini. 2013. Consumer perception of probiotic yogurt: Performance of check all that apply (CATA), projective mapping, sorting and intensity scale. Food Res. Int. 54:601-610. http:// dx.doi.org/10.1016/j.foodres.2013.07.056.

Daillant-Spinnler, B., and S. Issanchou. 1995. Influence of label and location of testing on acceptability of cream cheese varying in fat content. Appetite 24:101-105. http://dx.doi.org/10.1016/S01956663(95)99313-4.

Dalenberg, J. R., S. Gutjar, G. J. ter Horst, K. de Graaf, R. J. Renken, and G. Jager. 2014. Evoked emotions predict food choice. PLoS One 9:e115388. http://dx.doi.org/10.1371/journal.pone.0115388.

Danner, L., R. Ristic, T. E. Johnson, H. L. Meiselman, A. C. Hoek, D. W. Jeffery, and S. E. P. Bastian. 2016. Context and wine quality effects on consumers' mood, emotions, liking and willingness to pay for Australian Shiraz wines. Food Res. Int. http://dx.doi. org/10.1016/j.foodres.2016.08.006. In press.

De Pelsmaeker, S., J. Schouteten, and X. Gellynck. 2013. The consumption of flavored milk among a children population. The influence of beliefs and the association of brands with emotions. Appetite 71:279-286. http://dx.doi.org/10.1016/j.appet.2013.08.016.

De Steur, H., F. Vanhonacker, S. Feng, S. Xiaoping, W. Verbeke, and X. Gellynck. 2014. Cognitive biases and design effects in experimental auctions: An application to GM rice with health benefits. China Agric. Econ. Rev. 6:413-432. http://dx.doi.org/10.1108/ CAER-08-2013-0116
Deliza, R., and H. J. H. MacFie. 1996. The generation of sensory expectation by external cues and its effect on sensory perception and hedonic ratings: A review. J. Sens. Stud. 11:103-128. http:// dx.doi.org/10.1111/j.1745-459X.1996.tb00036.x.

Desai, N. T., L. Shepard, and M. A. Drake. 2013. Sensory properties and drivers of liking for Greek yogurts. J. Dairy Sci. 96:7454-7466. http://dx.doi.org/10.3168/jds.2013-6973.

Desmet, P. M. A., and H. N. J. Schifferstein. 2008. Sources of positive and negative emotions in food experience. Appetite 50:290-301. http://dx.doi.org/10.1016/j.appet.2007.08.003.

Di Monaco, R. S. Cavella, S. Di Marzo, and P. Masi. 2004. The effect of expectations generated by brand name on the acceptability of dried semolina pasta. Food Qual. Prefer. 15:429-437. http:// dx.doi.org/10.1016/j.foodqual.2003.07.003.

Dorado, R., C. Chaya, A. Tarrega, and J. Hort. 2016. The impact of using a written scenario when measuring emotional response to beer. Food Qual. Prefer. 50:38-47. http://dx.doi.org/10.1016/j. foodqual.2016.01.004.

Edwards, J. S. A., H. L. Meiselman, A. Edwards, and L. Lesher. 2003. The influence of eating location on the acceptability of identically prepared foods. Food Qual. Prefer. 14:647-652. http://dx.doi. org/10.1016/S0950-3293(02)00189-1.

Fernqvist, F. and L. Ekelund. 2014. Credence and the effect on consumer liking of food-A review. Food Qual. Prefer. 32, Part C:340353. http://dx.doi.org/10.1016/j.foodqual.2013.10.005.

Ferrarini, R., C. Carbognin, E. M. Casarotti, E. Nicolis, A. Nencini, and A. M. Meneghini. 2010. The emotional response to wine consumption. Food Qual. Prefer. 21:720-725. http://dx.doi. org/10.1016/j.foodqual.2010.06.004.

Gutjar, S., J. R. Dalenberg, C. de Graaf, R. A. de Wijk, A. Palascha, R. J. Renken, and G. Jager. 2015a. What reported food-evoked emotions may add: A model to predict consumer food choice. Food Qual. Prefer. 45:140-148. http://dx.doi.org/10.1016/j. foodqual.2015.06.008.

Gutjar, S., C. de Graaf, V. Kooijman, R. A. de Wijk, A. Nys, G. J. ter Horst, and G. Jager. 2015b. The role of emotions in food choice and liking. Food Res. Int. http://dx.doi.org/10.1016/j. foodres.2014.12.022.

Hellemann, U. A., D. J. Mela, J. I. Aaron, and R. Eleri Evans. 1993 Advances in Sensory Food Science Rose Marie Pangborn Memorial Symposium Role of fat in meal acceptance. Food Qual. Prefer. 4:90. http://dx.doi.org/10.1016/0950-3293(93)90359-E.

Hersleth, M., Ø. Ueland, H. Allain, and T. Næs. 2005. Consumer acceptance of cheese, influence of different testing conditions. Food Qual. Prefer. 16:103-110. http://dx.doi.org/10.1016/j. foodqual.2004.02.009.

Jaeger, S. R., M. K. Beresford, A. G. Paisley, L. Antúnez, L. Vidal, R. S. Cadena, A. Giménez, and G. Ares. 2015. Check-all-thatapply (CATA) questions for sensory product characterization by consumers: Investigations into the number of terms used in CATA questions. Food Qual. Prefer. 42:154-164. http://dx.doi. org/10.1016/j.foodqual.2015.02.003.

Jaeger, S. R., A. V. Cardello, and H. G. Schutz. 2013a. Emotion questionnaires: A consumer-centric perspective. Food Qual. Prefer. 30:229-241. http://dx.doi.org/10.1016/j.foodqual.2013.05.015.

Jaeger, S. R., S. L. Chheang, J. Yin, C. M. Bava, A. Gimenez, L. Vidal, and G. Ares. 2013b. Check-all-that-apply (CATA) responses elicited by consumers: Within-assessor reproducibility and stability of sensory product characterizations. Food Qual. Prefer. 30:5667. http://dx.doi.org/10.1016/j.foodqual.2013.04.009.

Jaeger, S. R., J. Hort, C. Porcherot, G. Ares, S. Pecore, and H. J. H. MacFie. 2016. Future directions in sensory and consumer science: Four perspectives and audience voting. Food Qual. Prefer. http:// dx.doi.org/10.1016/j.foodqual.2016.03.006.

Jiang, Y., J. M. King, and W. Prinyawiwatkul. 2014. A review of measurement and relationships between food, eating behavior and emotion. Trends Food Sci. Technol. 36:15-28. http://dx.doi. org/10.1016/j.tifs.2013.12.005.

Kenney, E., and K. Adhikari. 2016. Recent developments in identifying and quantifying emotions during food consumption. J. Sci. Food Agric. 96:3627-3630. http://dx.doi.org/10.1002/jsfa.7717. 
King, S. C., and H. L. Meiselman. 2010. Development of a method to measure consumer emotions associated with foods. Food Qual. Prefer. 21:168-177. http://dx.doi.org/10.1016/j.foodqual.2009.02.005.

King, S. C., H. L. Meiselman, and B. T. Carr. 2013. Measuring emotions associated with foods: Important elements of questionnaire and test design. Food Qual. Prefer. 28:8-16. http://dx.doi. org/10.1016/j.foodqual.2012.08.007.

King, S. C., H. L. Meiselman, A. W. Hottenstein, T. M. Work, and V. Cronk. 2007. The effects of contextual variables on food acceptability: A confirmatory study. Food Qual. Prefer. 18:58-65. http:// dx.doi.org/10.1016/j.foodqual.2005.07.014.

King, S. C., A. J. Weber, H. L. Meiselman, and N. Lv. 2004. The effect of meal situation, social interaction, physical environment and choice on food acceptability. Food Qual. Prefer. 15:645-653. http://dx.doi.org/10.1016/j.foodqual.2004.04.010.

Köster, E. P., and J. Mojet. 2015. From mood to food and from food to mood: A psychological perspective on the measurement of foodrelated emotions in consumer research. Food Res. Int. 76:180-191. http://dx.doi.org/10.1016/j.foodres.2015.04.006.

Kozlowska, K., M. Jeruszka, I. Matuszewska, W. Roszkowski, N. Barylko-Pikielna, and A. Brzozowska. 2003. Hedonic tests in different locations as predictors of apple juice consumption at home in elderly and young subjects. Food Qual. Prefer. 14:653-661. http://dx.doi.org/10.1016/S0950-3293(02)00207-0.

Lahne, J., A. B. Trubek, and M. L. Pelchat. 2014. Consumer sensory perception of cheese depends on context: A study using comment analysis and linear mixed models. Food Qual. Prefer. 32:184-197. http://dx.doi.org/10.1016/j.foodqual.2013.10.007.

Lane, R. D., and L. Nadel. 2002. Cognitive Neuroscience of Emotion. Oxford University Press, New York, NY.

Laros, F. J. M., and J. Steenkamp. 2005. Emotions in consumer behavior: A hierarchical approach. J. Bus. Res. 58:1437-1445. http:// dx.doi.org/10.1016/j.jbusres.2003.09.013.

Lawless, H. T., and H. Heymann. 2010. Sensory Evaluation of Food: Principles and Practices. 2nd ed. Springer, New York, NY.

Manzocco, L., A. Rumignani, and C. Lagazio. 2013. Emotional response to fruit salads with different visual quality. Food Qual. Prefer. 28:17-22. http://dx.doi.org/10.1016/j.foodqual.2012.08.014.

Meiselman, H. L. 2013. The future in sensory/consumer research: Evolving to a better science. Food Qual. Prefer. 27:208-214. http://dx.doi.org/10.1016/j.foodqual.2012.03.002.

Meyners, M., J. C. Castura, and B. T. Carr. 2013. Existing and new approaches for the analysis of CATA data. Food Qual. Prefer. 30:309-319. http://dx.doi.org/10.1016/j.foodqual.2013.06.010.

Meyners, M., S. R. Jaeger, and G. Ares. 2016. On the analysis of RateAll-That-Apply (RATA) data. Food Qual. Prefer. 49:1-10. http:// dx.doi.org/10.1016/j.foodqual.2015.11.003.

Mizutani, N., M. Okamoto, Y. Yamaguchi, Y. Kusakabe, I. Dan, and T. Yamanaka. 2010. Package images modulate flavor perception for orange juice. Food Qual. Prefer. 21:867-872. http://dx.doi. org/10.1016/j.foodqual.2010.05.010.

Mouta, J. S., N. C. de Sá, E. Menezes, and L. Melo. 2016. Effect of institutional sensory test location and consumer attitudes on acceptance of foods and beverages having different levels of processing. Food Qual. Prefer. 48, Part A:262-267. http://dx.doi. org/10.1016/j.foodqual.2015.10.002.

Ng, M., C. Chaya, and J. Hort. 2013a. Beyond liking: Comparing the measurement of emotional response using EsSense Profile and consumer defined check-all-that-apply methodologies. Food Qual. Prefer. 28:193-205. http://dx.doi.org/10.1016/j.foodqual.2012.08.012.

$\mathrm{Ng}$, M., C. Chaya, and J. Hort. 2013b. The influence of sensory and packaging cues on both liking and emotional, abstract and functional conceptualisations. Food Qual. Prefer. 29:146-156. http:// dx.doi.org/10.1016/j.foodqual.2013.03.006.

Oude Ophuis, P. A. M., and H. C. M. Van Trijp. 1995. Perceived quality: A market driven and consumer oriented approach. Food Qual. Prefer. 6:177-183. http://dx.doi.org/10.1016/0950-3293(94)00028$\mathrm{T}$.

Paasovaara, R., H. T. Luomala, T. Pohjanheimo, and M. Sandell. 2012. Understanding consumers' brand-induced food taste percep- tion: A comparison of 'brand familiarity' - and 'consumer valuebrand symbolism (in)congruity' - accounts. J. Consum. Behav. 11:11-20. http://dx.doi.org/10.1002/cb.356.

Piqueras-Fiszman, B., and S. R. Jaeger. 2014a. Emotion responses under evoked consumption contexts: A focus on the consumers' frequency of product consumption and the stability of responses. Food Qual. Prefer. 35:24-31. http://dx.doi.org/10.1016/j. foodqual.2014.01.007.

Piqueras-Fiszman, B., and S. R. Jaeger. 2014b. The impact of evoked consumption contexts and appropriateness on emotion responses. Food Qual. Prefer. 32:277-288. http://dx.doi.org/10.1016/j. foodqual.2013.09.002.

Piqueras-Fiszman, B., and S. R. Jaeger. 2014c. The impact of the means of context evocation on consumers' emotion associations towards eating occasions. Food Qual. Prefer. 37:61-70. http:// dx.doi.org/10.1016/j.foodqual.2014.04.017.

Piqueras-Fiszman, B., and C. Spence. 2011. Crossmodal correspondences in product packaging. Assessing color-flavor correspondences for potato chips (crisps). Appetite 57:753-757. 10.1016/j. appet.2011.07.012.

Pound, C., L. Duizer, and K. McDowell. 2000. Improved consumer product development. Part one: Is a laboratory necessary to assess consumer opinion? Br. Food J. 102:810-820. http://dx.doi. org $/ 10.1108 / 00070700010362239$.

Reinbach, H. C., D. Giacalone, L. M. Ribeiro, W. L. P. Bredie, and M. B. Frøst. 2014. Comparison of three sensory profiling methods based on consumer perception: CATA, CATA with intensity and Napping ${ }^{\circledR}$. Food Qual. Prefer. 32, Part B:160-166. http://dx.doi. org/10.1016/j.foodqual.2013.02.004.

Ryynänen, T., and A. Hakatie. 2014. "We must have the wrong consumers"-A case study on new food product development failure. Br. Food J. 116:707-722. http://dx.doi.org/10.1108/BFJ-082012-0215.

Schmuckler, M. A. 2001. What is ecological validity? A dimensional analysis. Infancy 2:419-436. 10.1207/S15327078IN0204_02.

Schouteten, J. J., H. De Steur, S. De Pelsmaeker, S. Lagast, I. De Bourdeaudhuij, and X. Gellynck. 2015a. Impact of health labels on flavor perception and emotional profiling: A consumer study on cheese. Nutrients 7:10251. 10.3390/nu7125533.

Schouteten, J. J., H. De Steur, S. De Pelsmaeker, S. Lagast, I. De Bourdeaudhuij, and X. Gellynck. 2015b. An integrated method for the emotional conceptualization and sensory characterization of food products: The EmoSensory ${ }^{\circledR}$ Wheel. Food Res. Int. 78:96107. http://dx.doi.org/10.1016/j.foodres.2015.11.001.

Schouteten, J. J., H. De Steur, S. De Pelsmaeker, S. Lagast, J. G. Juvinal, I. De Bourdeaudhuij, W. Verbeke, and X. Gellynck. 2016. Emotional and sensory profiling of insect-, plant- and meat-based burgers under blind, expected and informed conditions. Food Qual. Prefer. 52:27-31. http://dx.doi.org/10.1016/j. foodqual.2016.03.011.

Spinelli, S., C. Masi, C. Dinnella, G. P. Zoboli, and E. Monteleone. 2014. How does it make you feel? A new approach to measuring emotions in food product experience. Food Qual. Prefer. 37:109122. http://dx.doi.org/10.1016/j.foodqual.2013.11.009.

Spinelli, S., C. Masi, G. P. Zoboli, J. Prescott, and E. Monteleone. 2015. Emotional responses to branded and unbranded foods. Food Qual. Prefer. 42:1-11. http://dx.doi.org/10.1016/j.foodqual.2014.12.009. Stolzenbach, S., W. L. P. Bredie, R. H. B. Christensen, and D. V. Byrne. 2013. Impact of product information and repeated exposure on consumer liking, sensory perception and concept associations of local apple juice. Food Res. Int. 52:91-98. http://dx.doi. org/10.1016/j.foodres.2013.02.018.

Thomson, D. M. H. 2007. SensoEmotional optimization of food products and brands. Pages 281-303 in Consumer-Led Food Product Development. H. J. H. MacFie, ed. Woodhead Publishing Limited, Cambridge, UK.

Thomson, D. M. H. 2015. 5 - Expedited procedures for conceptual profiling of brands, products and packaging. Pages 91-118 in Rapid Sensory Profiling Techniques. J. Delarue, J. B. Lawlor, and M. Rogeaux, ed. Woodhead Publishing, Cambridge, UK. 
Thomson, D. M. H., and C. Crocker. 2013. A data-driven classification of feelings. Food Qual. Prefer. 27:137-152. http://dx.doi. org/10.1016/j.foodqual.2012.09.002.

Thomson, D. M. H., and C. Crocker. 2014. Development and evaluation of measurement tools for conceptual profiling of unbranded products. Food Qual. Prefer. 33:1-13. http://dx.doi.org/10.1016/j. foodqual.2013.10.008.

Thomson, D. M. H. and C. Crocker. 2015. Application of conceptual profiling in brand, packaging and product development. Food Qual. Prefer. 40, Part B:343-353. http://dx.doi.org/10.1016/j. foodqual.2014.04.013.

Thomson, D. M. H., C. Crocker, and C. G. Marketo. 2010. Linking sensory characteristics to emotions: An example using dark chocolate. Food Qual. Prefer. 21:1117-1125. http://dx.doi.org/10.1016/j. foodqual.2010.04.011.

Torres-Moreno, M., A. Tarrega, E. Torrescasana, and C. Blanch. 2012. Influence of label information on dark chocolate acceptability. Appetite 58:665-671. http://dx.doi.org/10.1016/j.appet.2011.12.005.

Valentin, D., S. Chollet, M. Lelievre, and H. Abdi. 2012. Quick and dirty but still pretty good: A review of new descriptive methods in food science. Int. J. Food Sci. Technol. 47:1563-1578. http:// dx.doi.org/10.1111/j.1365-2621.2012.03022.x.

van Kleef, E., H. C. M. van Trijp, and P. Luning. 2005. Consumer research in the early stages of new product development: A critical review of methods and techniques. Food Qual. Prefer. 16:181-201. http://dx.doi.org/10.1016/j.foodqual.2004.05.012.

Varela, P., and G. Ares. 2012. Sensory profiling, the blurred line between sensory and consumer science. A review of novel methods for product characterization. Food Res. Int. 48:893-908. http:// dx.doi.org/10.1016/j.foodres.2012.06.037.

Vidal, L., C. Barreiro, B. Gómez, G. Ares, and A. Giménez. 2013. Influence of information on consumers' evaluations using check-allthat-apply questions and sorting: A case study with milk desserts. J. Sens. Stud. 28:125-137. http://dx.doi.org/10.1111/joss.12030.

Villegas, B., I. Carbonell, and E. Costell. 2008. Effects of product information and consumer attitudes on responses to milk and soybean vanilla beverages. J. Sci. Food Agric. 88:2426-2434. http:// dx.doi.org/10.1002/jsfa.3347. 